\title{
IMPLEMENTASI VISI PROFETIK: BERMAKRIFAT MELALUI HUTAN
}

\author{
HM. Nasruddin Anshoriy Ch. \\ Pengasuh Pesan Trend Budaya Ilmu Giri \\ Dusun Nogosari, Desa Selopamioro, Imogiri, Bantul, Yogyakarta 55782 \\ E-mail: nasrudin.anshori@yahoo.com \\ HP. +62-811251923
}

Abstract: This article discusses about a teaching to respect all God's creating to build a harmonious relation. Understanding the human beings leads the people to understand God's character. The object of the research is the forest and it is analyzed philosophically by revealing the meaning inside. It is found that there is a dialectic among the forest, human, and God which is essential for man's life. Beside that, by protecting the forest the people as a leader (khalifah) can be closer to God.

Abstrak: Tulisan ini membahas tentang ajaran untuk menghormati makhluk ciptaan tuhan agar terjadi hubungan yang harmonis. Dengan memahami makhluk hidup di dunia ini, sejatinya mengarahkan manusia untuk memahami sifat-sifat Tuhan. Kerangka tulisan ini mengkaji hutan dari ranah filosofis dengan mengungkap makna yang terkandung di dalamnya. Hasilnya, ada dialektika antara hutan, manusia, dan tuhan bagi keberlangsungan hidup ini. Selain itu, dengan menjaga hutan, manusia pun turut mendekatkan diri pada Tuhan karena mengemban amat sebagai khalifah.

Kata Kunci: Tuhan, Hutan, Manusia, Hidup, Zaman.

\section{A. Pendahuluan}

Di sebuah pesan trend sederhana yang berada di pegunungan seribu, Jogja bagian selatan, yang dikelilingi oleh hutan jati yang rindang, seorang Kyai sedang bersemangat mengajarkan "sesuatu" kepada santri-santrinya. Ia duduk di sebuah mushalla bambu menghadap para santri yang mengitarinya. Di tangan kirinya, ada sebilah kapak dalam genggaman, di tangan kanannya ada bibit pohon. Kyai itu berkata,

"Santri-santriku yang aku cintai, saya ada satu permainan... Caranya begini, di tangan kiriku ada sebilah kapak, di tangan kananku ada bibit pohon. Jika 
saya angkat bibit pohon ini, maka berserulah kalian “Tanam!”, jika saya angkat kapak ini, maka teriaklah "Tebang!".

Santri-santrinya pun mengerti dan mengikuti. Sang Kyai berganti-gantian mengangkat antara tangan kanan dan tangan kirinya. Semakin lama semakin cepat. Beberapa saat kemudian, Sang Kyai kembali berkata, "Baik, sekarang perhatikan. Jika saya angkat bibit pohon, maka sebutlah "Tebang!", jika saya angkat kapak, maka katakanlah "Tanam!". Perkataan itu diulanginya seperti tadi. Tentu saja, para santri tadi keliru dan kikuk, dan sangat sukar untuk mengubahnya. Namun lambat laun, mereka sudah biasa dan tidak lagi kikuk. Selang beberapa saat, permainan berhenti.

Sang Kyai tersenyum kepada santri-santrinya. Begitulah pola hidup umat manusia hidup di dunia. Mulanya yang baik itu baik, yang salah itu salah. Manusia begitu jelas membedakannya. Namun kemudian, muncul nafsu dan godaan dalam diri yang memaksakan kepada manusia dengan berbagai cara, untuk menukarkan sesuatu, dari yang baik menjadi jahat, dan sebaliknya. Pertama-tama, mungkin akan sukar bagi manusia menerima hal tersebut, tapi karena terus disosialisasikan dan dikampanyekan dengan cara-cara menarik, akhirnya lambat laun pun terbiasa dengan hal itu (Anshory Ch., 2008: 4). Tanpa sadar, mereka mulai dapat mengikutinya. Materialisme, kapitalisme, dan konsumerisme yang kemudian menjelma menjadi ketamakan, keserakahan, dan kerakusan, tidak pernah berhenti membalik dan menukar nilai dan etika dalam hidup (Skolimowski, 2004: 15) sehingga manusia yang seharusnya terus menanam, malah tak henti-hentinya menebang.

Kisah tersebut dimaksudkan agar dalam diri para santri tumbuh kesadaran dalam jiwa untuk bisa membedakan baik-buruk dalam kerangka yang lebih luas, yang mencakup tak hanya hubungan manusia dengan Sang Khalik, atau hubungan manusia dengan sesama manusia, tapi juga hubungan manusia dengan lingkungannya. It ulah salah satu cara mengaji, mengajarkan etika kehidupan, agar para santrinya sanggup memaknai "apa arti hidup" dan bagaimana sebuah moralitas harus dijalankan. Konsep ajaran tersebut berpegang teguh pada firman Allah pada Nabi SAW yang menyebutkan: "Tidak Aku utus engkau wahai Muhammad, selain untuk memperbaiki akhlak manusia!”.

Para pecinta lingkungan di seluruh dunia sudah berulangkali menabuh genderang peringatan kepada siapa pun yang akan mendiami planet bumi ini tentang hak-hak dasar generasi masa depan untuk mewarisi bioregion yang sehat, yang baik dan yang terpelihara kelestariannya. Secara manusiawi dan akal sehat, tidaklah adil meninggalkan bioregion yang rusak dan hancur di 
planet bumi ini bagi anak cucu manusia nanti. Menebang pohon hanya untuk memenuhi ketamakan dan kerakusan adalah tidak logis, tidak bermoral, dan jelas melecehkan kehidupan dan kemanusiaan. Pemberhalaan ekonomi, pendewaan aspek bisnis dan kecerobohan cara pandang yang menempatkan politik sebagai panglima ternyata telah melecehkan dimensi spiritual dalam zona martabat kemanusiaan (Skolimowski, 2004: 17). Dengan dalih dan argumen apa pun, pemakaian teknologi modern dan bahan kimia yang merusak seperti merkuri, kadmium, arsenik, serta berbagai macam racun-racun kimia lainnya, jelas menyengsarakan nilai-nilai kemanusiaan itu sendiri.

\section{B. Mencari Tuhan di dalam Hutan}

Kekayaan alam yang tak tergantikan (non-renewable) perlu lebih diperhatikan. Hal ini karena daya dukung lingkungan merupakan sakaguru bagi terselenggaranya pembangunan yang berkelanjutan. Banjir yang menggelontor dan menggenangi hampir 70 persen kawasan di Jabodetabek jelas menggambarkan betapa suramnya bioregion di kota metropolitan seperti Jakarta berikut kota-kota satelit di sekelilingnya.

Hal yang terasa aneh, hingga kini kian tersebarnya informasi, wacana, dan kajian tentang penyelamatan lingkungan ternyata berbanding lurus dengan kian parahnya kerusakan lingkungan. Sudah tak terhitung banyaknya jumlah publikasi yang menubuahkan keniscayaan akan penyelamatan lingkungan, namun kehadiran publikasi itu berkejaran dengan kecepatan laju kerusakan lingkungan sendiri. Dalam perspektif kehutanan pun setali tiga uang, makin banyak aturan dan undang-undang tata kelola kehutanan, yang terjadi justru makin rusaknya jutaan hektar hutan di bumi Indonesia.

Tak bisa dielakkan, manusia kemudian dikepung oleh situasi yang penuh ironi dan penuh paradoks: lingkungan semakin mengalami degradasi di tengahtengah kian ramainya orang berbicara tentang penyelamatan lingkungan (Anshory Ch., 2008: 46). Tidak mengherankan jika banjir yang menghantam wilayah-wilayah padat manusia di kawasan urban dan tanah longsor yang menimbun rumah-rumah penduduk di lereng bukit pun tak bisa lagi dipahami secara sederhana sebagai bencana, tragedi, disaster atau katastrofa yang semata ditimbulkan oleh alam. Apa boleh buat, situasi tragis ini pun harus dipahami secara kolektif sebagai kesalahan bersama seluruh umat manusia yang sangat bercorak teknokratis dan kapitalistik. Singkatnya, kerusakan hutan dan hancurnya lingkungan adalah akibat ulah dan ketamakan manusia.

Di hutan, pohon-pohon tua itu kini nyaris sudah tak tersisa. Demikian pula pohon-pohon muda, juga terus ditumbangkan. Pohon-pohon yang terus ber- 
dzikir dan berdoa itu kini telah rebah oleh mesin-mesin berupa gergaji raksasa. Tak ada yang menangis, tak ada yang merasa kehilangan, dan tak ada pula yang berbelasungkawa, kecuali rintih perih dari dalam rimba itu sendiri. Pohon tua di hutan itu tumbang, beberapa pohon lain di sampingnya ikut roboh dan terbentuklah ruangan di dalam hutan yang tembus ke langit dengan lebar setinggi pohon yang disebut rumpang. Melalui mulut rumpang, sinar matahari masuk ke lantai hutan dan merangsang pertumbuhan permudaan tingkat semai yang sudah menunggu di lantai hutan. Selang 70 tahun, terbentuklah kembali tegakan berlapis.

Secara fisik, hutan adalah mosaik rumpang dan tegakan berlapis dari berbagai bentuk dan umur. Desain hutan berupa mosaik rumpang inilah yang harus dilestarikan karena berperan melangsungkan regenerasi hutan, menciptakan keragaman organisme hutan dan membuat populasi organisme hutan tetap seimbang. Begitulah teorinya, menurut para rimbawan (Anshory Ch., 2008: 89).

Masih menurut teori, hutan ditunt ut untuk berfungsi ekonomis, ekologis, dan meningkatkan perekonomian penduduk setempat. Dengan sistem ekologi, hutan sangat sensitif terhadap perlakuan, terutama pembukaan kanopi, maka sebidang hutan tidak akan mampu memenuhi semua tuntutan di atas secara simultan (Skolimowski, 2004: 7). Seperti halnya bulldozer, hut an pun mempunyai batas kemampuan. Sebab itu, lahan kehutanan Indonesia dibagi ke dalam 3 macam misi. Pertama, unit pengelolaan hutan konservasi untuk misi ekologis dengan perlakuan doing nothing. Kedua, unit pengelolaan kebun kayu (timber plantation) untuk misi ekonomis dengan perlakuan tree farming atau budi daya pohon secara intensif. Ketiga, unit pengelolaan hutan produksi (areal HPH) untuk misi ekologis dan ekomonis yang sama penting dengan perlakuan gap simulation cutting (tebang simulasi rumpang) secara ekstensif yaitu sebanyak 50 persen dari luas petak diperuntukkan untuk fungsi ekologis dan 50 persen untuk fungsi ekonomis

Makna hutan itu sendiri lebih jauh dari sekadar teori itu. Hutan juga bermakna pendidikan, hutan juga berarti peradaban, hutan juga sebuah ranah spiritual yang memperkokoh dan mengasah keimanan. Adanya hutan juga membuktikan adanya rahmat dan karunia Tuhan. Premisnya adalah jika hutan telah dilahap dengan rakus sekadar untuk memenuhi nafsu ketamakan, maka artinya Tuhan telah disingkirkan at as nama kebatilan dan keserakahan. Tuhan telah dihilangkan dan ayat-ayatNya yang terlihat begitu jelas dan indah melalui hijau hutan telah dimusnahkan. 
Titik temu antara "hutan" dan "Tuhan" tentu dengan perspektif keimanan. Lebih dari 14 abad silam, di jazirah tandus Saudi Arabia, seorang Sahabat bertanya kepada Nabi Muhammad SAW:

Wahai Rasulullah, apakah kami dapat melihat Tuhan pada Hari Pembalasan? Sang Rasul pun bersabda: Apakah kalian terhalang melihat bulan di malam purnama? Sahabat itu menjawab: Tidak, wahai Sang Junjunjang. Rasulullah lantas bertanya: Apakah kalian terhalang melihat matahari yang tidak tertutup awan? Sahabat itu menjawab: Tidak, wahai Rasulullah. Lalu Sang Nabi kembali bersabda: Seperti itulah kalian akan melihat Tuhan. Barangsiapa yang menyembah sesuatu, maka ia mengikuti sembahannya itu. Orang yang menyembah matahari akan mengikuti matahari, orang yang menyembah bulan akan mengikuti bulan, orang yang menyembah berhala akan mengikuti berhala. (Abu Hurairah, T.T.).

Hidup ini begitu singkat, dan karena itu manusia perlu berusaha untuk terus menemukan Tuhan, tak terkecuali di tengah-tengah hutan. Sejujurnya, rahasia hutan dalam tafsir makrifat itu bermula dari renungan dan pengalaman, dan tentu akan disajikan kembali ke hadapan manusia sebagai bahan renungan. Penulis masih percaya bahwa pada dasarnya manusia adalah makhluk yang bisa mendengarkan nasihat. Meski anehnya, mayoritas mereka tidak melakukannya. Hutan yang manusia renungkan ini hanyalah sebuah gambaran. Manusialah sebenarnya yang menjadi rimbanya; menjadi hutannya. Dalam makna yang lain, hutan adalah amanah Tuhan.

Mengapa penulis memilih "hutan" sebagai ungkapan makrifat tentang rahasia kehidupan umat manusia dalam Mencari Tuhan? Apakah karena hutan menyimpan rahasia-rahasia yang terpendam dalam rimbanya? Bukankah pohon itu sendiri merupakan ibu kandung yang memberikan kehidupan berupa oksigen bagi semua makhluk hidup? Ia diciptakan sebagai makhluk yang paling berserah diri pada Sang Khalik, yang paling menerima takdirnya hingga mati, tak pernah beranjak dari tempat asalnya walau terik menyengat dan hujan deras mengguyurnya? Pohon adalah makhluk yang terus memberi dan tak pernah sekalipun meminta. Tak ada jeruk minum jeruk, tak ada durian makan durian, tak mungkin ada apel melahap apel lain, mustahil ada jati menerkam jati. Kenapa manusia begitu rakus dan tamak selalu ingin menebangnya?

Biarlah pertanyaan makrifat di atas terus berdesir di hati orang-orang yang beriman bersama kekhusyukan pohon-pohon di dalam hutan yang daundaunnya terus bergetar sebagai tanda sedang berdzikir. Jika 'arasy Allah ada di atas air, maka 'arasy Allah itu selalu dikelilingi oleh hutan belantara yang terusmenerus memelihara dan menyimpan air melalui akar-akar pohonnya. Itulah 
rahasia yang hanya dapat dijawab oleh Allah (Breton, 2003: 67). Rahasia itu akan bertambah rahasia dan tiada akan terkurangi kerahasiaannya.

Begitu pula hutan cintanya kaum sufi. Ia juga sebuah rahasia. Sungguh, kaum sufi adalah sosok yang haus akan haki-kat yang ada dalam hutan kehidupan. Terkadang orang yang 'Arif Billah menulis hakikat itu di atas air, dan terkadang mereka berjalan di atasnya. Namun demikian, orang-orang yang haus akan hakikat itu kadangkala justru jauh lebih utama daripada mereka yang mampu berjalan di atas air. Suatu fenomena yang sangat aneh dan membingungkan, tapi tidak boleh diabaikan.

\section{Hutan Sumber Peradaban: Sumber Ilmu Tuhan}

Jika manusia renungkan, tidak ada satu makhluk pun—tidak juga babiyang mengotori sarangnya dengan bebas seperti yang dilakukan homo sapiens, yang meracuni habitatnya dengan bahan-bahan kimia yang jahat dan sampah beracunnya yang mematikan. Sebuah rawa-rawa bangkai manusia yang membusuk sedang menunggu manusia, kecuali ada penawar yang segera diterapkan. Seperti sudah ditakdirkan Tuhan, penawar sekaratnya bumi memang ada, berfungsi, dan bisa membawa manusia kembali pada kehidupan yang sehat.

Bukti bahwa bumi sedang sakit—hampir tidak bisa diperbaiki lagi—cukup jelas bagi penerima hadiah Nobel, Carrel pada tahun 1912. Dalam buku Man, The Unknown, ilmuwan terkemuka dari Perancis ini memperingatkan karena "tanah merupakan dasar bagi kehidupan seluruh manusia", maka satu-satunya harapan manusia bagi dunia yang sehat terletak pada penegakan kembali keselarasan pada tanah yang telah manusia ganggu dengan metode pertanian modern. Menurut Carrel, seluruh kehidupan bisa sehat ataupun sakit, tergantung pada kesuburan tanah. Baik langsung maupun tak langsung, semua makanan berasal dari tanah.

Sekarang ini, tanah telah kelelahan, bekerja melampaui batas, terkuras, sakit, teracuni oleh pupuk-pupuk kimia. Oleh karenanya, kualitas makanan juga menderita, demikian pula kesehatan. Kekurangan gizi berawal dari tanah. Kesehatan manusia tergant ung pada makanan yang sehat, dan ini hanya bisa berasal dari tanah yang subur dan produktif. Mineral-mineral dalam tanah, mengendalikan metabolisme sel-sel dalam tanaman, binatang dan manusia. Penyakit-penyakit terutama tercipta karena penghancuran keselarasan yang terjalin di antara zat mineral yang ada dalam jumlah sangat kecil dalam udara, air, makanan, dan yang paling penting dalam tanah (Anshory Ch., 2008: 67). Jika tanah kekurangan unsur tadi, makanan dan air juga akan kekurangan. 
Carrel lalu berkesimpulan bahwa pupuk kimia tidak dapat mengembalikan kesuburan tanah. Pupuk-pupuk tadi tidak bekerja dalam tanah melainkan secara paksa diminumkan pada tanaman, dan meracuni tanaman sekaligus tanah. Hanyalah humus organik yang bisa menghidupkan tanah. Tanaman, ujar Carrel, adalah perantara yang hebat, yang membuat unsur-unsur batuan-yang diubah oleh mikroorganisme menjadi humus — bisa menjadi makanan binatang dan manusia, untuk dibangun menjadi daging, tulang, dan darah. Sebaliknya, pupuk kimia tidak bisa menambahkan kandungan humus ataupun menggantikan perannya dalam tanah. Pupuk kimia menghancurkan sifat-sifat fisik tanah. Ketika pupuk kimia diberikan pada tanah, mereka larut dan mencari gabungan alami dengan mineral yang telah ada. Gabungan-gabungan baru ini akan melimpahi atau membebani tanaman, membuatnya menjadi tidak seimbang.

Tanaman yang dipupuk kimia boleh jadi kelihatan subur, tapi suburnya itu menghasilkan jaringan yang berair, rawan penyakit; dan kualitas proteinnya buruk. Pupuk kimia yang meningkatkan jumlah panen tanpa mengganti semua unsur yang dihabiskan dari tanah, telah mempengaruhi berubahnya nilai gizi bahan makanan pokok manusia: "semakin maju suatu peradaban, semakin jauh ia dari makanan alami." Jenis makanan manusia saat ini mengandung makanan yang dipalsukan dan tidak alami: dengan pewarnaan, pemutihan, pemanasan, dan pengawetan, yang menghilangkan unsur-unsur gizi penting yang berharga. Pasteurisasi pada susu akan mematikan enzim yang penting bagi pencernaan, dan hanya menyisakan bangkai-bangkai bakteri yang membusuk. Susu juga menjadi sumber kedua — setelah daging — residu pestisida dalam makanan di Amerika Serikat. Gandum putih, yang secara mengecoh disebut "diperkaya," telah dihilangkan bakal bijinya, padahal itu mengandung zat-zat gizi yang penting.

Mereka yang hidup sebelum Perang Dunia II, khususnya di Eropa tahu bahwa roti, buah, sayuran dan daging yang ada sekarang amat berbeda dengan zaman dulu. Hasil panenan manusia boleh jadi lipat dua atau tiga, tapi kualitas gizinya telah berkurang drastis. Tampilan makanan telah menjadi faktor yang terpenting, padahal siapapun tahu bahwa makanan yang indah tadi tak lebih dari hiasan dan pajangan beku di toko-toko swalayan yang kehilangan nilai gizinya.

Jumlah yang berlimpah bukan berarti makanan itu mengandung cukup jumlah unsur dan vitamin yang diperlukan. Tidak diragukan lagi, ujar Dr. Melchior Dikkers, Profesor Biokimia dan Kimia Organik di Loyola University, bahwa kekurangan gizi adalah masalah terpenting yang dihadapi umat manusia sekarang ini. Setiap dua detik, ada seorang anak yang mati kelaparan; dan yang 
mengejutkan ada 60 juta orang dewasa yang mati tiap tahun. Amerika Serikat, dengan mengesampingkan produksi makanan yang dibangga-banggakan, nyata sekali kurang gizi. Meskipun pengeluaran per kapita masyarakat AS untuk perawatan kesehatan adalah yang tertinggi di dunia, tapi kasus kanker, kegemukan, serangan jantung, dan penyakit peredaran darah juga tertinggi.

Itulah bukti-bukti nyata perihal keblinger-nya umat manusia modern di puncak kecerdasannya. Lantas, bagaimana upaya manusia membangun peradaban di tengah-tengah krisis kemanusiaan seperti dewasa ini? Membangun peradaban baru demi terciptanya "kota Tuhan" sebagaimana yang menjadi gagasan para filosof sejak zaman lampau, memang membutuhkan pendekat an yang bersifat holistik, perencanaan yang komprehensif, serta syarat yang lengkap. Substansi dari peradaban baru adalah terbangunnya masyarakat yang beradab, pembangunan yang memanusiakan manusia, terkelolanya alam dengan baik, serta terjalin hubungan yang indah antara manusia dengan Tuhan (Anshory Ch., 2008: 106). Di dalam budaya Jawa muncul istilah "hamamayu hayuning bawana", sementara para pakar ekologi menyebut "sustainable development", sedangkan menurut al-Qur'an dinamai "memakmurkan bumi". Pertanyaan yang relevan untuk diajukan ialah, bagaimana peradaban baru dibangun dalam perspektif kehutanan dan lingkungan hidup?

Dalam sebuah diskusi santai beberapa tahun silam, pakar lingkungan hidup Soemarwoto mengatakan, bahwa "sebenarnya ketergantungan manusia pada makhluk hidup lain jauh lebih besar dibandingkan ketergant ungan makhluk hidup lain pada manusia". Sekadar contoh, manusia tidak dapat hidup apabila tidak ada tumbuhan. Hanya karena tumbuhan hijaulah, maka energi matahari dapat diikat melalui fotosintesis, dimana manusia dan hewan hanya bisa hidup dari energi yang diikat oleh tumbuhan hijau tersebut. Sebagaimana telah diajarkan oleh guru biologi sejak manusia di SLTP, dalam proses fotosintesis itulah diproduksi oksigen yang diperlukan manusia untuk pernafasannya. Tanpa oksigen itu, manusia jelas tidak bisa bertahan hidup. Sebaliknya, tumbuh-tumbuhan yang begitu berjasa pada manusia itu jauh lebih mandiri karena ia tidak memerlukan manusia untuk hidup.

Contoh lain adalah hewan. Hampir segala jenis hewan bisa hidup tanpa perlu keberadaan manusia. Oleh karena itu, manusia yang merasa dirinya paling penting dan paling berkuasa di muka bumi, sebenarnya adalah makhluk yang paling lemah dan paling rentan (Murata, 2005). Apabila manusia tidak berhatihati, secara cepat maupun lambat akan membuat dirinya punah. Hal inilah yang saat ini menjadi agenda penting para ahli, pemerhati dan aktivis lingkungan. 
Keserakahan dan ketamakan manusia telah merampas setiap hak hidup makhluk lain, misalnya melalui penggundulan hutan, pencemaran air dan udara oleh mesin-mesin industri, berbagai bentuk penambangan yang tidak mengindahkan analisis dampak lingkungan, percobaan senjata nuklir, limbah B3, serta berbagai tindakan ceroboh manusia lain. Akibat keserakahan dan ketamakan manusia itu, maka akan berakibat fatal bagi bumi, yaitu mengubah kondisi bumi sehingga tidak lagi dapat dihuni oleh manusia (Anshory Ch., 2008: 234).

Jika nenek moyang atau suku-suku primitif yang tinggal di pedalaman mempunyai kearifan lokal dan kepekaan alamiah untuk menghargai lingkungan alam, dengan cara merawat, mengelola dan melestarikannya melalui pemanfaatan sebatas kebutuhan, maka dewasa ini "kearifan lokal" tersebut mulai punah akibat keserakahan dan ketamakan manusia. Jika pada masyarakat primitif sudah terdapat "kearifan lokal" yang bermakna menyadari bahwa manusia adalah bagian dari ekosistem, maka tidak demikian dengan masyarakat manusia dewasa ini. Konon di negara-negara maju, dewasa ini dengan gencar tengah digalakkan kampanye yang berbunyi: man is a part of the ecosystem and not apart from the ecosystem.

Makna dari kampanye penyadaran lingkungan bahwa "manusia adalah bagian dari ekosistem dan bukan terpisah dari ekosistem tersebut" dimaksudkan agar masyarakat modern lebih hati-hati di dalam mengeksploitasi lingkungan sehingga kerusakan pada bumi bisa segera dipulihkan dan kehidupan manusia bisa diselamatkan (Anshory Ch., 2008: 56). Gerakan penyelamatan lingkungan atau yang dikenal dengan istilah green spirit atau gerakan hijau kembali digalakkan di negara-negara maju sebagai upaya serius menyelamatkan bumi dan manusia dari kepunahan. Singkatnya, menjadikan hutan sebagai sumber peradaban.

\section{Menanam Sampai Kiamat: Kebaktian pada Tuhan}

Dewasa ini, di negara-negara maju kesadaran bahwa manusia adalah bagian dari ekosistem telah mulai tumbuh dan makin kuat. Kesadaran ini muncul karena dengan ilmu pengetahuannya mereka mengetahui adanya bahaya serius akibat kerusakan tata kelola lingkungan bagi manusia. Mereka mengetahui bahwa matahari dengan suhunya yang tinggi memancarkan sinar yang bergelombang pendek seperti sinar ultra-violet. Sinar yang bergelombang pendek itu mengandung energi yang tinggi yang mampu merusak sel-sel hidup. Namun sinar ultra-violet yang bergelombang pendek itu ditahan oleh lapisan ozon yang terdapat di lapisan stratosfer sehingga makhluk hidup di bumi terlindung dari penyinaran yang berbahaya itu. 
Sejak dua dasawarsa lalu, para ahli di negara-negara maju sudah dapat mendeteksi adanya penurunan kadar ozon di lapisan stratosfer yang diakibatkan oleh adanya zat kimia yang disebut klorofluorokarbon atau biasa disebut gas CFC. Dengan ilmu dan teknologi, masyarakat ilmiah di Barat juga mengetahui adanya efek rumah kaca (ERK), yaitu naiknya suhu di bumi yang pada gilirannya akan menimbulkan pemanasan global. Apa yang kemudian terjadi? Pemanasan global ini akan mempunyai dampak global pula, yaitu perubahan iklim dan kenaikan permukaan laut yang jelas-jelas akan membahayakan manusia.

Sementara itu, gas karbondioksida $\left(\mathrm{CO}_{2}\right)$ yang dihasilkan sebagai buangan industri, kendaraan bermotor, dan bahan bakar fosil tersebut telah pula membalut bumi ini sehingga panas matahari tidak bisa keluar dan menjadikan bumi semakin panas. Akibatnya adalah lautan semakin mekar dan bongkahan es di kutub bumi mulai mencair sehingga diperkirakan akan menaikkan permukaan air laut sebanyak $65 \mathrm{~cm}$ dan mengancam tenggelamnya negara kepulauan seperti Maldives dan Pasifik Selatan.

Lebih jauh, para pakar lingkungan hidup mengatakan bahwa bumi yang semakin panas juga mempengaruhi cuaca iklim yang diramalkan akan berubah, sehingga produksi pertanian, curah hujan dan gejala alam lainnya terganggu. Radiasi yang ditimbulkan akibat percobaan senjata nuklir, limbah B3 dan limbah kimia dari pabrik maupun bahan cemar dari industri yang dibuang ke udara, jelas akan bereaksi secara kimia dengan butir-butir air sehingga tercipta hujan asam yang membunuh ikan di permukaan air serta pohon-pohon. Termasuk di dalamnya adalah pemakaian pupuk kimia secara terus-menerus dengan volume tinggi, jelas bukan hanya merusak hara tanah melainkan juga menjadikan pori-pori tanah tersumbat dan tanah-tanah pertanian menjadi tidak produktif.

Emil Salim, bahkan dengan tegas menyebut, bahwa keanekaragaman hayati (biodiversity) kini semakin menyempit akibat berkurangnya areal hutan di muka bumi, khususnya hutan hujan tropis yang menjadi sarang pembiakan plasma nutfah (genetics) yang digunakan sebagai bahan masukan utama dalam bioteknologi untuk menghasilkan pangan, obat-obatan, kosmetika dan bahan industri. Semua ini mencerminkan bahwa fungsi tatanan lingkungan atau ekosistem di bumi ini sudah terganggu akibat limbah proses pembangunan yang bersifat konvensional.

Sebagaimana telah manusia pahami, di dalam ekosistem, semua zat, materi dan makhluk saling berkaitan dan saling menghidupi dalam perputaran siklus 
yang tidak berakhir selagi mata rantai komponen ekosistem tetap ut uh. Semakin beraneka ragam isi ekosistem, semakin banyak jaringan antar komponen ekosistem, dan semakin stabil ekosistem berfungsi (Anshory Ch., 2008: 190). Jika komponen dalam ekosistem saling berkaitan, serba beragam, saling mengisi, serasi dan selaras, maka perikehidupan ekosistem ini dapat berlanjut.

Pola pembangunan berkelanjutan sendiri, sebagaimana disampaikan oleh Koesnadi Hardjasoemantri pada saat Dialog Budaya bertema "Membangun Peradaban Baru" di Kraton Kilen Yogyakarta beberapa tahun silam, tidak terbatas pada pola pengelolaan sumber alam secara berkelanjutan. Tak kurang penting adalah mengembangkan keberlanjutan sosial atau social sustainability yang berkaitan erat dengan ketahanan sosial at au social resilience. Di dalam masyarakat terdapat ambang batas sosial, di atas mana gejolak sosial akan meletup.

Let upan sosial ini akan terjadi apabila proses pembangunan tidak tidak memberi peluang bagi masyarakat untuk turut berpartisipasi dan mendapatkan manfaat dari adanya pembangunan (Iqbal, 2002: 24). Ketika kesempatan untuk meningkatkan kualitas diri melalui perbaikan kesehatan, kesempatan pendidikan, peluang yang terbuka at au ready access untuk memperoleh resources seperti tanah, lapangan kerja, modal, serta berbagai sumber-sumber kehidupan lain. Let upan sosial dapat pula terjadi apabila hasil pembangunan terbagi timpang, sehingga menimbulkan kesenjangan sosial. Demikian pula di sektor kehutanan. Ringkas kata, jika hutan terus dijarah dengan dalih dan kilah apa pun, maka ambang batas itu cepat atau lambat akan menjadi bencana kemanusiaan.

\section{E. Simpulan}

Ada dialektika antara hutan, manusia, dan tuhan bagi keberlangsungan hidup ini. Hal itu termanifestasi dalam hubungan kausal dan kepemimpinan manusia dalam memahami bahwa segala yang ada di dunia ini adalah milik Allah. Selain itu, dengan menjaga hutan, manusia pun turut mendekatkan diri pada Tuhan karena mengemban amat sebagai khalifah. Kesadaran umat manusia untuk mencintai, melestarikan dan menempatkan hutan sebagai amanah Tuhan akan terus berkembang dan menjadi bagian dari prinsip hidup yang bermakna "berlomba-lomba dalam kebajikan". Selebihnya, Bismillah menanam, Bismillah melestarikan dan Allahu Akbar terus berjihad menyelamatkan hutan adalah wujud dari implementasi visi profetik. 


\section{Daftar Pustaka}

Anshoriy Ch., HM Nasruddin. 2008. Kearifan Lingkungan dalam Perspektif Budaya Jawa. Jakarta: Yayasan Obor Indonesia.

Breton, Denise dan Christopher Largent. 2003. Cinta, Jiwa, \& Kebebasan di Jalan Sufi. Bandung: Pustaka Hidayah.

Iqbal, Muhammad. 2002. Rekonstruksi Pemikiran Agama dalam Islam (The Reconstruction of Religious Thought in Islam), Terj. Osman Raliby. Yogyakarta: Jalasutra.

Murata, Sachiko dan William C. Chittick. 2005. The Vision of Islam, Terj. Yogyakarta: Suluh Press.

Skolimowski, Henryk. 2005. Philosophy for New Civilization. Gyan Publishing House.

Surin, Bachtiar. 1978. Terjemahan \& Tafsir Al-Qur'an; 30 Juz Huruf Arab \& Latin. Bandung: Fa Sumatra. 